SIR,

\section{Dyeing of snow surfaces to observe snow structure}

When undertaking research in snow accumulation or mechanics, investigators often find it important to obtain a clear, visual perspective and obtain good photographic evidence of the snow stratigraphy in the vertical wall of a snow pit. Trafficability, snow accumulation, melt percolation and bearing-capacity studies are research areas that frequently require the observation of snow morphology. Smoking (sooting), back lighting, spray painting and dyeing the snow surface are several techniques that have been used to obtain the desired visual result (Bader and others, 1954; Lanyon, 1959; Benson, 1962).

Sooting a vertical snow surface has been accomplished using vehicular exhaust, smudge pots and burning oil rags near the snow wall. Although observable stratigraphic and deformation features could be seen in the snow, more detail is frequently desired. Spray painting of the snow surface found its place in some research studies but the technique did not prove satisfactory in our snow-pit observations. At temperatures below $-10^{\circ} \mathrm{C}$, the paint would become too viscous to apply properly.

Studies made at Camp Century, Greenland, on anchors, footings and pile foundations led to a need to obtain good visual and photographic views of natural snow stratigraphy and the morphology associated with various snow-loading deformation processes. Smoking techniques could not be used in the below-surface trenches where the testing was done. Dyeing the snow surface using writing ink diluted in methyl alcohol or methylene coloring dissolved in methyl alcohol were tried. Alcohol was used as the liquid to prevent freeze-up problems that occurred with the use of water. We found that both coloring agents worked well. However, we preferred a methylene blue or green dye because these colors produced the best highlighting of snow structure. Other methylene-dye colors, such as orange, yellow and red, tended to highlight the snow morphology less clearly.

The methylene-dye powder and alcohol were mixed by stirring. Only a very small amount of coloring was required as a dark solution produces a very undesirable dark snow surface in which fine density variations are masked. As each user will have a different dyeing need, the dye preparation should begin with a small quantity of methylene coloring: about the volume of a pencil eraser added to a liter of alcohol. Additional coloring can then be added to the alcohol until the desired snow stratgraphic/morphologic structure highlighting is produced.

The surface of the snow to be observed was planed smooth in a manner that limited nick or chip marks that could collect excess dye on their edges. In a photograph, these dyed areas may appear to represent a natural or load-induced snow structure or an ice lens. A sharp-edged steel scraper was a good surface-smoothing device. In hard-to-reach places, a stiff putty knife was also helpful. To further improve the surfaces, a stiff paintbrush was used to brush loose fines from the prepared pit wall. In high-density snow $\left(>0.45 \mathrm{Mg} \mathrm{m}^{-3}\right)$, a mechanical planing device was used to remove the more severe gouges and cuts produced by the tools used to excavate the snow pit.
An electric spray-gun was used in our program to spray the dye uniformly on the prepared surface. If the dye is not applied uniformly, the resulting snow-color contrast seen in a photograph could be mistaken for an area of different density. A 1 liter hand-held garden sprayer, which is pressurized through the use of a built-in hand pump, can be used, provided the pressure is kept up.

After the snow surface is dyed, natural stratigraphy and variations in snow density caused by load-induced deformation were clearly visible. The structural detail in the snow could be further highlighted by applying a small amount of heat. The heat produced a very thin film of water that migrated into the snow pores for a very short distance. Through this movement, the dye was dispersed into places where it did not otherwise reach.

A blow torch or an infrared propane heater was used at Camp Century, where the pit snow-surface temperature was about $-20^{\circ} \mathrm{C}$. A relatively uniform flow of heat (no hot spots) must be applied to the surface. For this reason, the propane-fired infrared heater proved best. It must be understood that only a small amount of heat is needed. Too much heat will glaze the surface or cause the dye to run. Glazing will cause the surface to turn white. If either of the above events occur, the features that one wishes to observe will no longer be sharp and clear. Heating is probably not needed where the snow temperature is above $-10^{\circ} \mathrm{C}$.

To obtain a photograph showing sharper snowstructure detail, one can auger a hole or cut a trench behind the prepared surface. In tunnels or dark areas, lights are then placed in the hole to illuminate the snow from behind.

The following photographs were selected to show that dyed snow-pit walls, where the snow density varied from 0.5 to $0.6 \mathrm{Mg} \mathrm{m}^{-3}$, give a striking view of the snow structure. Figure 1 shows a snow-pit wall surface, beside a 10 in $[0.25 \mathrm{~m}]$ diameter steel pile. It was difficult to distinguish strata, densified snow, etc., from within the pit, and not possible to see snow structure in a photograph of the undyed wall. In the dyed area,

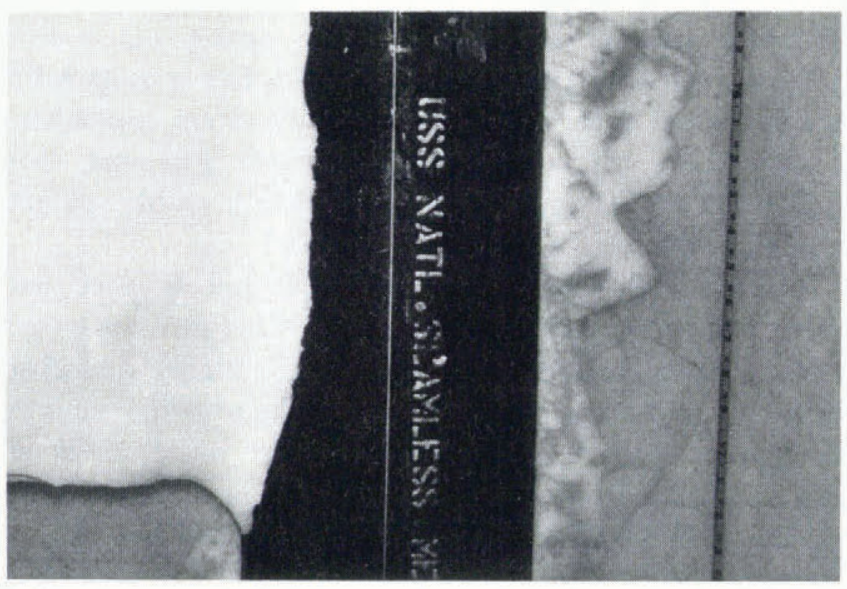

Fig. 1. Snow stratigraphy and displacement patterns beside a 10 in $[0.25 \mathrm{~m}]$ diameter, closed-ended steel pile driven into $0.54 \mathrm{Mg} \mathrm{m}^{-3}$ density snow. Note the absence of visible snow structure in the undyed area at the left. 


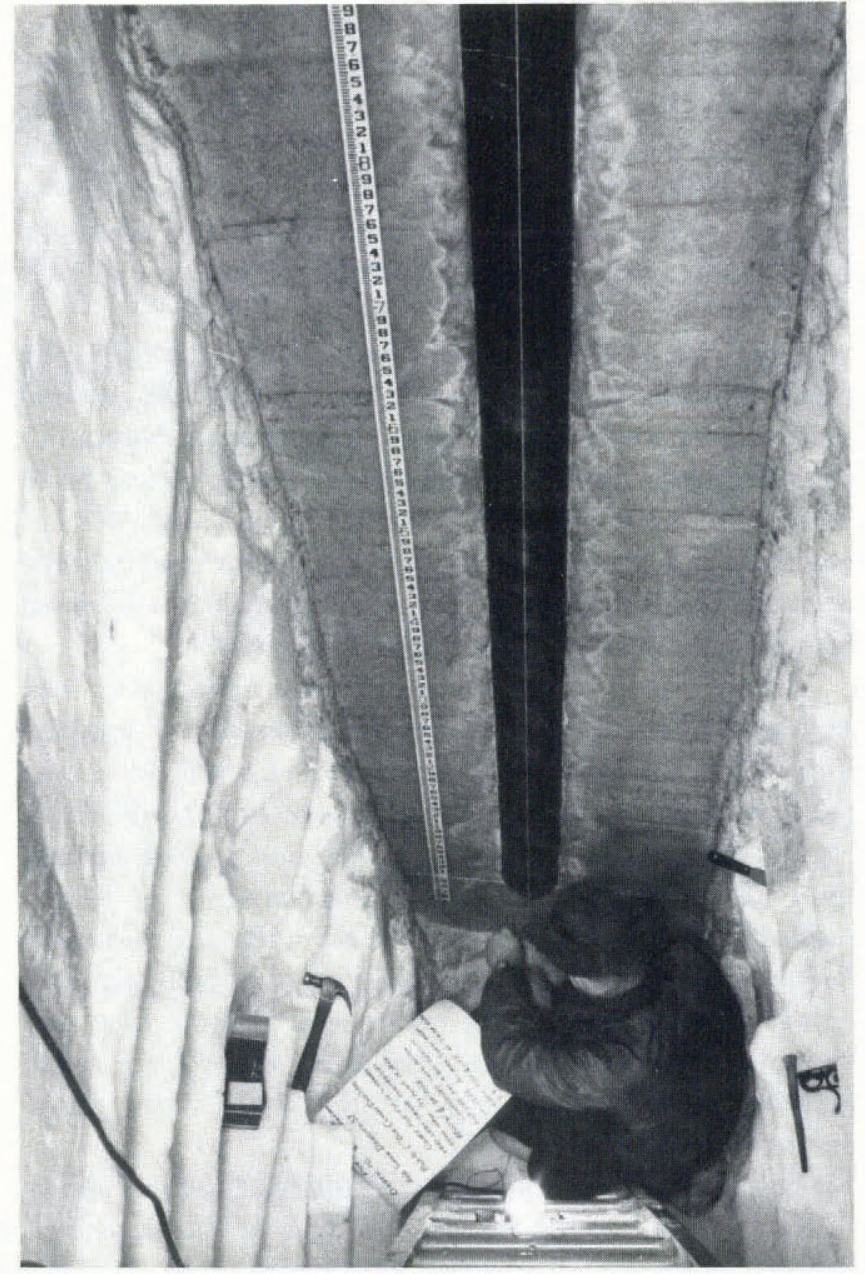

Fig. 2. Looking down into a snow pit that was excavated with the use of an electric chain saw. The pit was excavated to reveal the snow displacement along a 6 in [0.15 $\mathrm{m}]$ diameter, close-ended pipe pile driven into $\sim 0.54 \mathrm{Mg} \mathrm{m}^{-3}$ density snow. After planing the pit wall smooth and then dyeing the surface, the natural stratigraphic layering became visible.

stratigraphic layering and the snow displaced during pile-driving are easily seen in Figure 2.

Figure 3 is a photograph of a block of snow that was removed from around the base of a square 6 in $\times 6$ in $[0.15 \mathrm{~m} \times 0.15 \mathrm{~m}]$ timber pile. The surface was sprayed with dye and then lit from behind. The snow block was about $0.3 \mathrm{~m}$ thick. Snow-displacement patterns that developed during pile-driving are clearly visible, as are the natural ice lenses.

Figures 4 through 6 show other pit-wall surfaces that were planed smooth and then dyed. One can easily see the natural stratigraphy, as well as the highly densified and displaced snow produced when piles were driven into the snow. The dye did not stain the white areas of displaced snow because this snow was compressed to a density above $0.85 \mathrm{Mg} \mathrm{m}^{-3}$ and therefore had a very low porosity.

Additional comments that could be made on the piles and snow-displacement patterns visible in the above photographs would not be within the scope of this correspondence. Further information may be sought in

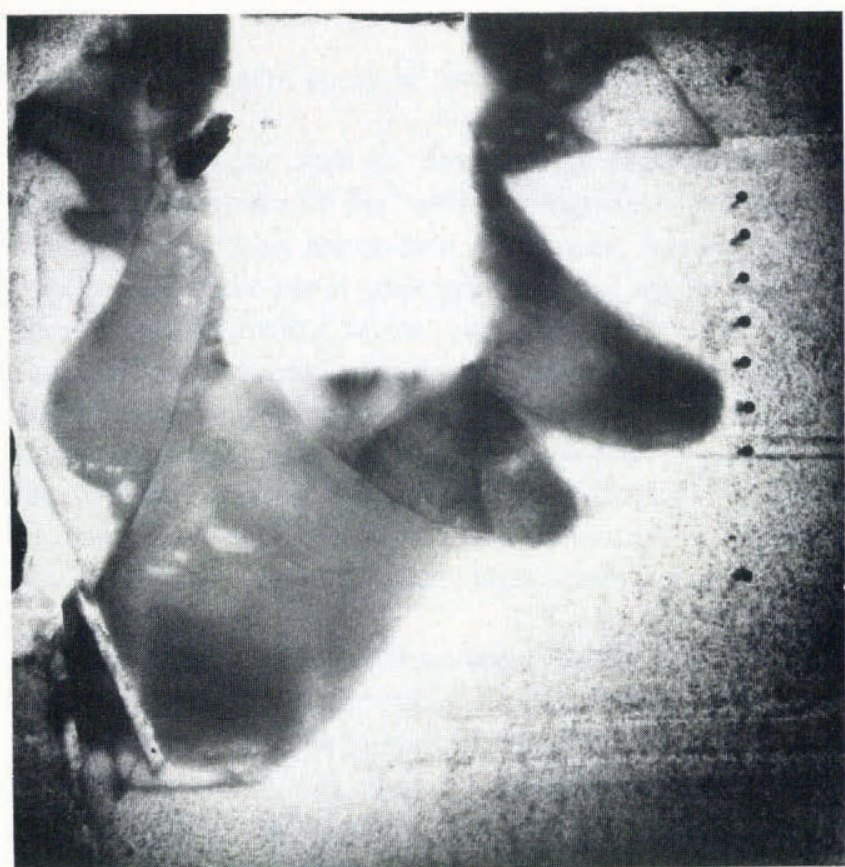

Fig. 3. Densified and displaced snow at the base of the 6 in $\times 6$ in $[0.15 \mathrm{~m} \times 0.15 \mathrm{~m}]$ timber pile shown in Figure 1. The aligned nail heads, at the center right side of the snow block, are spaced 1 in [25.4 mm] apart. This photograph was taken using back lighting after the face of the block had been dyed.

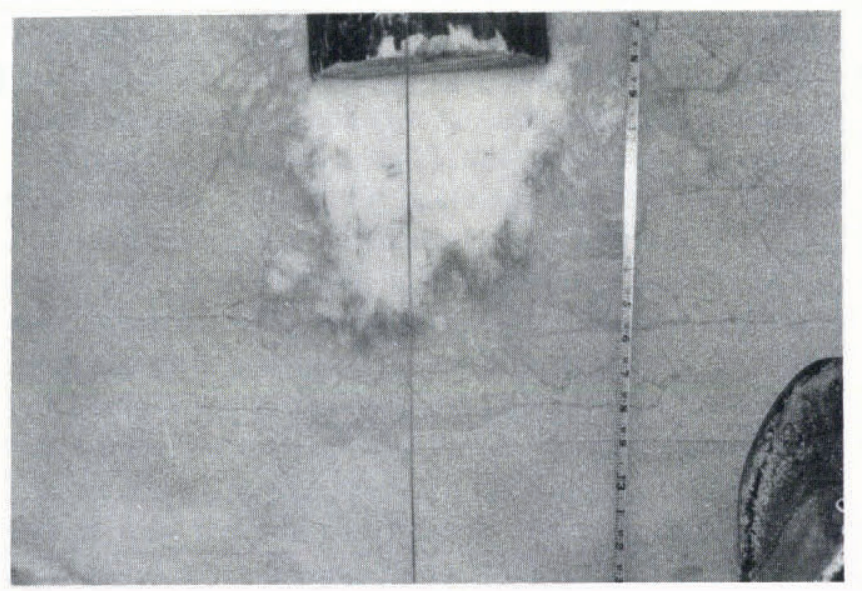

Fig. 4. Densified and displaced snow patterns below a previously load tested, tapered timber pile.

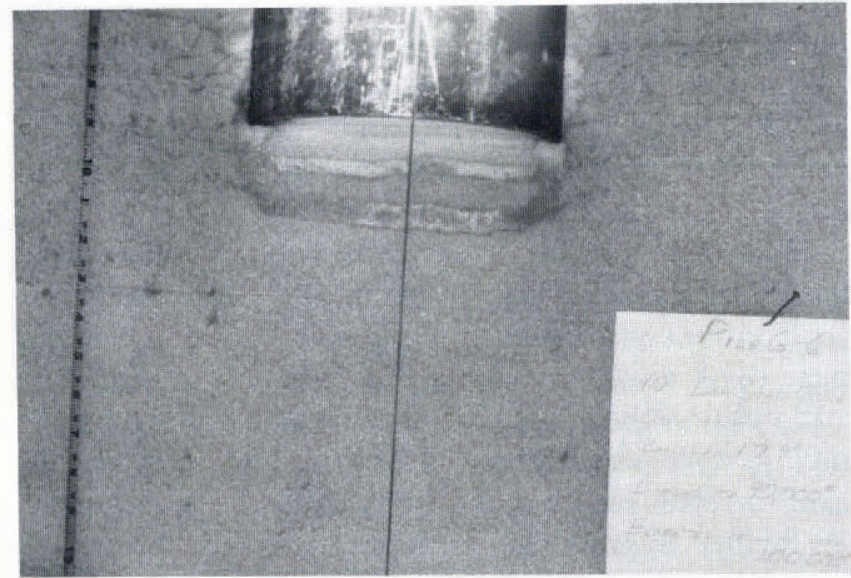

Fig. 5. Densified and displaced snow patterns at the base of a previously load tested, 10 in [0.25 m] diameter, openended steel pile driven $\sim 5.5 \mathrm{~m}$ below the trench floor. 


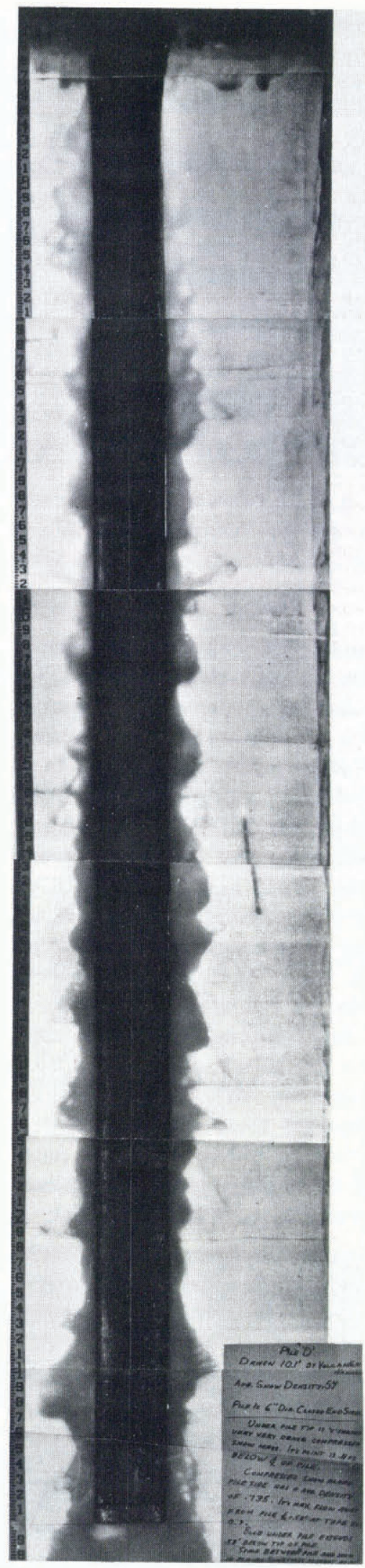

Fig. 6. Snow stratigraphy and displacement patterns beside a 6 in $[0.15 \mathrm{~m}]$ diameter, close-ended steel pile driven $10.1 \mathrm{ft}[3.1 \mathrm{~m}]$ below the trench floor. The snow structure was highlighted by illuminating the snow from within a borehole behind the pile. The near-vertical dark line on the right side of the pile at about the middle of the composite photograph is a chain-saw cut. a report on pile foundations by Kovacs (1976). The photographs presented here are only intended to give an indication of the results that can be obtained from first planing smooth the surface of a snow-pit wall and then applying a dye to reveal snow structure. Each investigator will need to develop, through trial and error, the procedure best suited to producing a good view of the snow structure.

In our field program, we did not obtain satisfactory results using a dye of methanol coloring in water. Freezeup at the sprayer nozzle was one problem and the snow surface had a blemished appearance because of the addition of the water, which then froze. Freeze-up may not be a problem at elevated temepratures, say above about $-3^{\circ} \mathrm{C}$. However, the addition of water to the surface may cause undesirable snow modification. A methylenecolored alcohol dye does not do this because much of the alcohol evaporates.

It should be pointed out that one should be careful when handling the methylene-dye powder, as it is a difficult dye to remove from hands and clothing.

\section{U.S. Army Cold Regions Research and Engineering Laboratory, Hanover,} New Hampshire 03755-1290, U.S.A.

\section{January 1993}

\section{REFERENCES}

Bader, H., R. Haefeli, E. Bucher, J. Neher, O. Eckel and C. Thams. 1954. Snow and its metamorphism. SIPRE Translation 4.

Benson, C.S. 1962. Stratigraphic studies in the snow and firn of the Greenland ice sheet. SIPRE Rep. 70.

Kovacs, A. 1976. Study of piles installed in polar snow. CRREL Rep. 7623.

Lanyon, J.J. 1959. Studies on vehicular trafficability of snow. Part II. SIPRE Rep. 35.

The accuracy of references in the text and in this list is the responsibility of the author, to whom queries should be addressed.

SIR,

The use of computer-aided learning packages in glaciology and glacial geology

One of the recent changes in computing has been the development of more user-friendly computer environments. One specific example is the development of HyperCard (discussed in detail in Nielsen (1990)), which provides development tools for interactive packages which are ideal for developing computer-aided learning (CAL) programmes. These have been developed for 